\title{
The prevalence of depression among Iranian infertile couples: an update systematic review and meta-analysis
}

\author{
Yousef Alimohamadi ${ }^{1,2}$, Ahmad Mehri ${ }^{2}$, Mojtaba Sepandi ${ }^{3,4}$, Firooz Esmaeilzadeh ${ }^{5}$ and Roya Rashti $6^{*}$
}

\begin{abstract}
Background: Depression is a common mental disorder. Infertility can lead to depression. The current systematic review and meta-analysis were conducted to estimate the pooled prevalence of depression among Iranian infertile couples. Seven electronic databases (Google Scholar, Maglran, SID, Science Direct, PubMed, Scopus, Web of Science) were searched, up to August 2019, for relevant published studies. The pooled prevalence of depression also pooled mean of depression score was determined using a random-effects model with a 95\% confidence interval (95\% Cl). All analyses performed using Stata ver11 (Stata Corporation, College Station, TX, USA). The 0.05 was considered a significant level.

The main body: Totally, 230 studies were retrieved and 31 studies included in the meta-analysis. The pooled prevalence of depression among infertile couples was about 35.3\% (95 \% Cl 24.1-46.5), and the prevalence of depression among females and males was $48.7 \%$ (95\% Cl 24.0-73.3) and 9\% (95\% Cl 0\% to 23.7\%), respectively.

Conclusions: Our findings suggest a high prevalence of depression in infertile couples. The results can highlight an important and growing mental disorder among infertile couples that may be overlooked.
\end{abstract}

Keywords: Prevalence, Depression, Iranian, Infertile couples

\section{Background}

Infertility is a reproductive system deficiency defined by the "failure to achieve a clinical pregnancy after 12 months or more of regular unprotected sexual intercourse" $[1,2]$. The overall burden of subfertility/infertility is high globally, and it seems the trend of this deficiency does not have a decreasing trend. According to reports of the World Health Organization, over 10\% of women are affected by infertility [2].. Also, according to results of Demographic and Health Surveys (DHS) data (2004), about 186 million married women at reproductive age have infertility deficiency in developing countries [3]. In Iran, the prevalence of primary infertility based on the WHO's clinical, epidemiological, and

\footnotetext{
*Correspondence: roya.rashti73@gmail.com

${ }^{6}$ Social Determinants of Health Research Center, Research Institute for Health Development, Kurdistan University of Medical Sciences, Sanandaj, Iran Full list of author information is available at the end of the article
}

demographic definitions was 20.2, 12.8 , and 9.2\%, respectively. In addition, the prevalence of secondary infertility was about $4.9 \%$ [4]. Infertility affects various aspects of life including mental, social, and physical aspects $[5,6]$. Also, this disorder can lead to shame, stigma, anxiety, depression, and low feelings of selfesteem and guilt [7]. One of the more prevalent disorders among infertile couples especially among females is depression [8-10]. About $86 \%$ of infertile couples experience it [11]. Depression is defined by a sense of persistent sadness and a loss of enjoyment in activities, accompanied by an inability to carry out daily activities, for at least 2 weeks [12]. This mental disorder has a negative impact on the process of infertility treatment, the follow-up stage also the hope for treatment [13]. Feeling depressed and frustrated can reduce infertile women's satisfaction with the past, present, and future lives [14]. It is estimated that about 25 to $60 \%$ of infertile 
couples suffered at least one psychological disorder [15] and globally depression affected more than 300 million people of all ages [16]. The prevalence of depression among Iranian infertile couples was estimated 0.47 in 2013 [11]. Many studies have been conducted to estimate the prevalence of depression among Iranian infertile couples, which are widely reported. Also, a systematic review conducted up to 2011 [11] the prevalence of this mental disorder among Iranian infertile couples maybe change over time. Therefore, the purpose of the current systematic review and meta-analysis was to estimate a pooled measure of the prevalence of depression among Iranian infertile couples between 2005 and 2019.

\section{Methods}

\section{Materials and methods}

The current meta-analysis was performed based on the Preferred Reporting Items for Systematic Reviews and Meta-Analyzes (PRISMA) and Meta-analysis of Observational Studies in Epidemiology (MOOSE).

\section{Search strategy}

In this study, articles published from January 2005 to August 2019 through 7 electronic databases (Google Scholar, MagIran, SID, Science Direct, PubMed, Scopus, Web of Science) were searched. The keywords were as follows: Infertility, Sterility, Sterile, Iran, Depressions, Depressive Disorder, Bipolar Disorder, Unipolar Disorder, Emotional Depressions, Depressive Symptom Were examined. The search was conducted in Persian and English languages. The search strategy of the databases was done independently by two researchers, and the dispute was resolved by a third person.

\section{Screening and selection criteria}

We included all published cross-sectional studies between 2005 and 2019 that estimated the prevalence of depression or mean and standard deviation of depression score among Iranian infertile couples. Also, the casecontrol, cohort, clinical trial, case reports, and case series studies were excluded. In addition, studies that did not

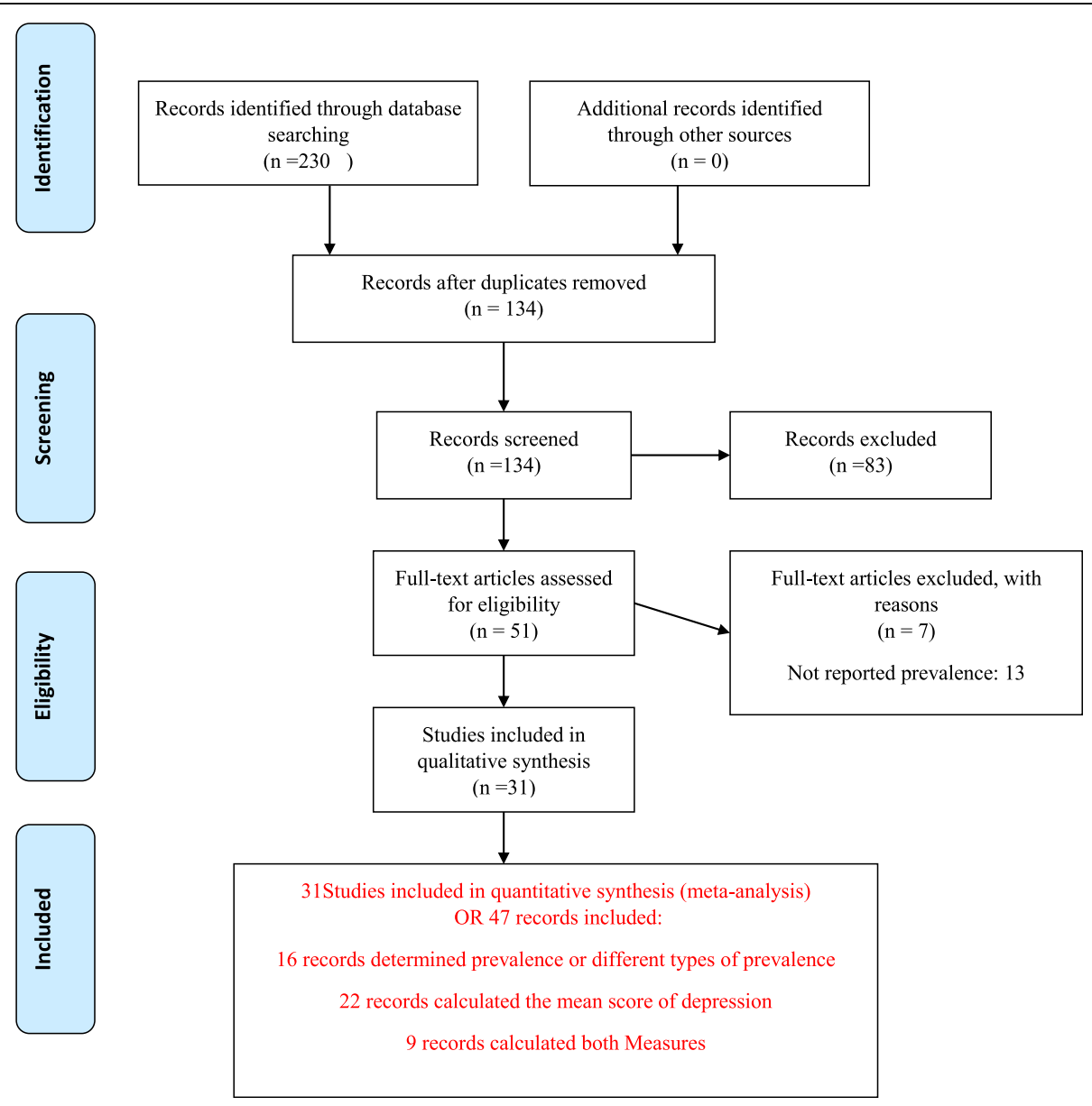

Fig. 1 The process of searching and selection of articles 


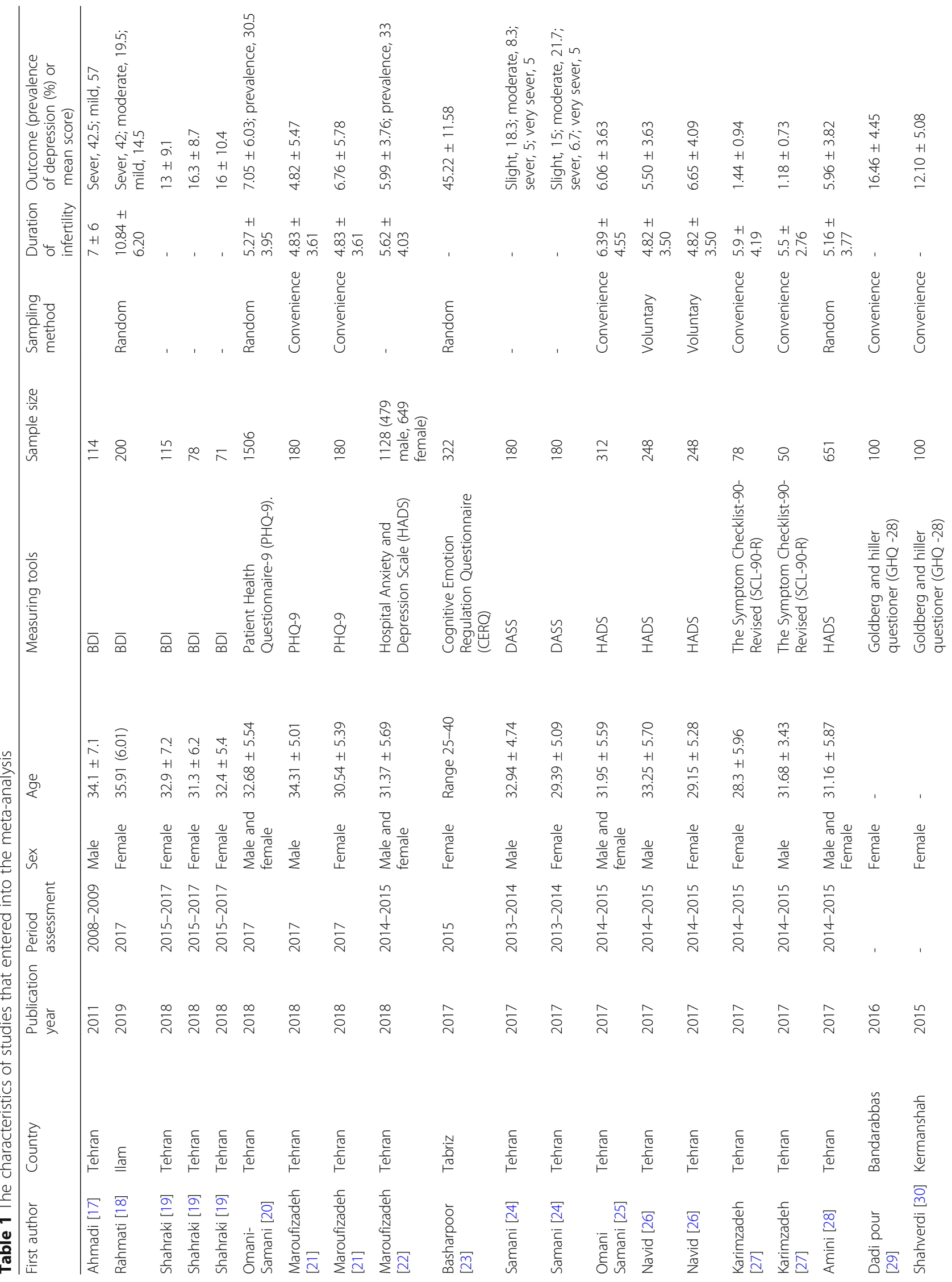




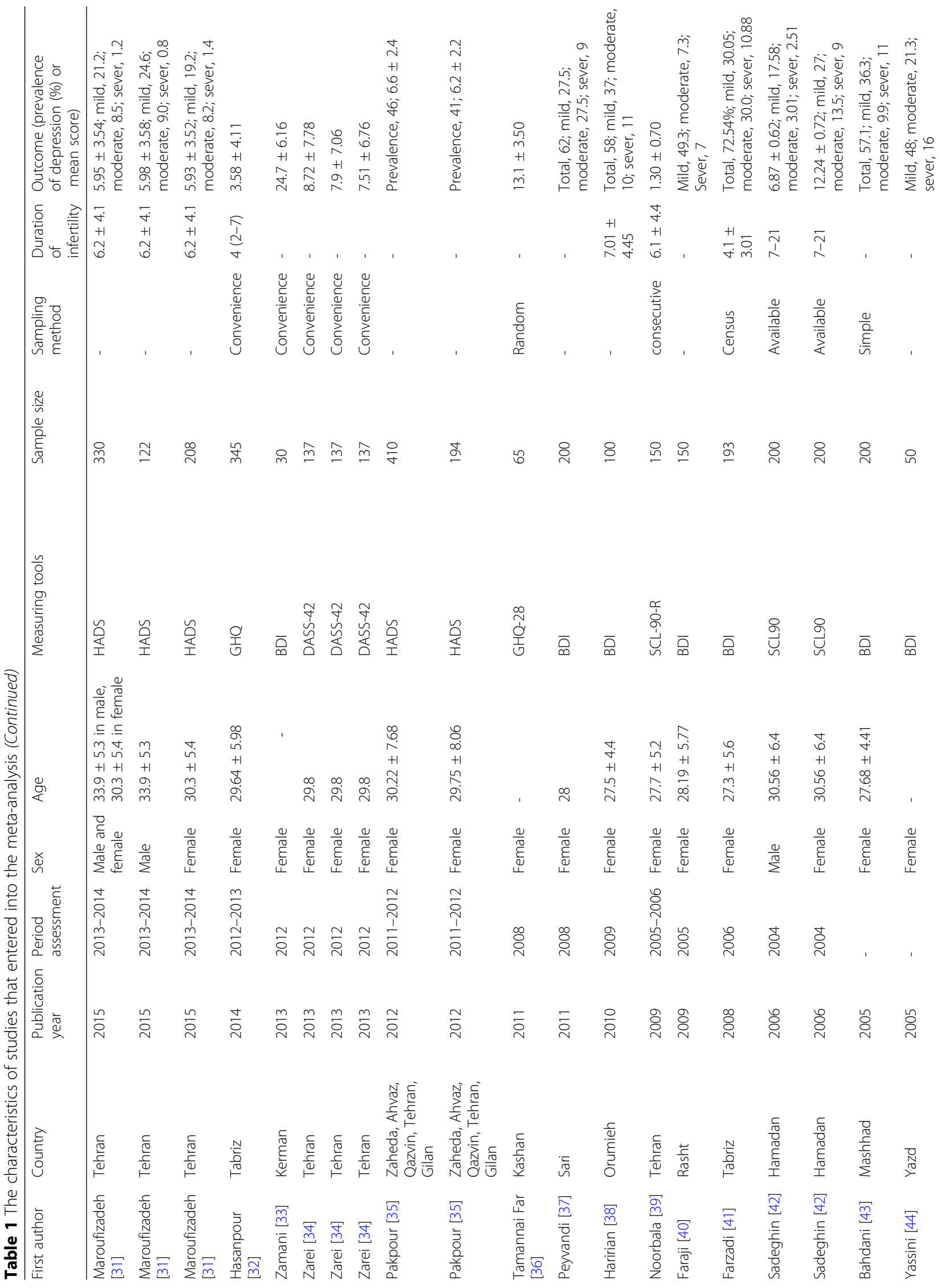




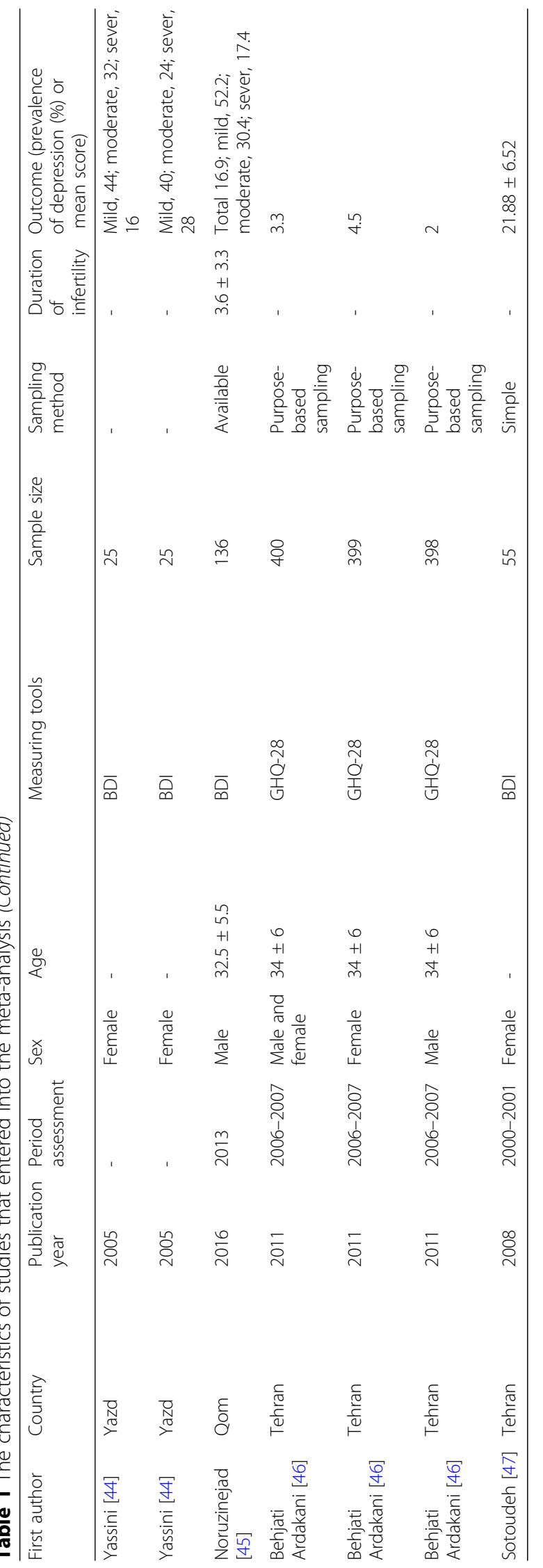


Table 2 The pooled and subgroup depression prevalence among Iranian couples

\begin{tabular}{|c|c|c|c|c|c|}
\hline Variable & Number of records & Sample size & Prevalence ( $95 \%$ confidence interval) & $T^{2}$ & $R^{2}(\%)$ \\
\hline \multicolumn{6}{|l|}{ Gender } \\
\hline Females & 7 & 1696 & $48.7(24.0-73.3)$ & 0.11 & 99.3 \\
\hline Males & 2 & 534 & $9(0-23.7)$ & 0.01 & 95.1 \\
\hline Both gender & 3 & 3034 & $22(2-42)$ & 0.03 & 99.6 \\
\hline \multicolumn{6}{|l|}{ Type of questionnaire } \\
\hline $\mathrm{BDI}$ & 5 & 829 & $53.3(32.8-73.8)$ & 0.05 & 97.7 \\
\hline Patients Health Questionnaire-9 (PHQ-9) & 1 & 1506 & $30.5(28.2-32.8)$ & - & - \\
\hline HADS & 3 & 1732 & $39.8(30.8-48.8)$ & 0.005 & 91.2 \\
\hline Goldberg and Hiller Questioner (GHQ) & 3 & 1197 & $3(1-4.5)$ & 0.001 & 52.6 \\
\hline Overall prevalence & 12 & 5264 & $35.3(24.1-46.5)$ & 0.03 & 99.4 \\
\hline
\end{tabular}

provide an accurate report about the prevalence of depression (or mean and standard deviation of the depression score) in the infertile population, as well as studies that did not use a standard questionnaire to measure depression, were excluded.

\section{Quality and risk of bias assessment}

An 8-item checklist was used for critical appraisal and risk of bias assessment of the studies. This checklist includes items such as Clearly define depression, clearly definite infertility, Give the eligibility, Give precision of the estimates, indicate the study's design, Explain sample size calculation, describe the locations, and describe the dates [11].

\section{Data extraction}

The data extraction form was included (1) author's name, (2) country, (3) year of performing and publication, (4) sex, (5) mean and standard deviation of age, (6) measuring tools, (7) sample size, (8) sampling method, (9) mean and standard deviation of duration infertility, (10) mean and standard deviation of duration marriage, and (11) and mean and standard deviation or prevalence of depression in infertile couples. All data were extracted independently by two authors. Also, some studies estimated different types of depression (mild, moderate, severe) among infertile couples. So the pooled prevalence of the mentioned subgroup was calculated separately.

\section{Statistical analysis}

The heterogeneity between studies was assessed using $I^{2}$ and $T^{2}$ (Tau2) statistics. Due to the presence of heterogeneity between studies ( $I^{2}$ more than $90 \%$ and $T^{2}$ statistic), the pooled prevalence of depression also pooled mean of depression score was determined using a random-effects model with 95\% confidence interval (CI). The weight of each study was determined using the inverse variance model. The univariate meta-regression was conducted to determine the probable cause of heterogeneity between studies. Also, the pooled estimate was estimated according to different subgroups. Begg and Egger's tests were used to assess publication bias. All analyses performed using Stata ver11 (Stata Corporation, College Station, TX, USA). The 0.05 was considered a significant level.

\section{Results}

As it is shown in Fig. 1, a total of 230 articles were found in the databases. After eliminating duplicates, screening the titles and abstracts of the articles, 51 articles were selected for full-text review. Of these, 20 studies were excluded because did not report the prevalence and were not cross-sectional study. Finally, 31 articles with 47 records were included in the study (Fig. 1). The general characteristics of the articles are listed in Table 1.The overall prevalence of depression among infertile couples was about $35.3 \%$ [ $(95 \% \mathrm{CI}$ 24.1-46.5), $I^{2}$ 99.4, $T^{2} 0.03 P$ heterogeneity $\left.<0.001\right]$.

Table 3 The pooled prevalence of mild, moderate, and severe depression among Iranian infertile couples

\begin{tabular}{lllll}
\hline Type of depression & Number of records & Sample size & Prevalence (95\%confidence interval) & $T^{2}$ \\
\hline Mild & 18 & 2813 & $31.2(25.4-36.9)$ & 0.01 \\
Moderate & 17 & 2699 & $15.4(11.5-19.4)$ & 92.0 \\
Severe & 18 & 2813 & $13.7(9-17.6)$ & 0.005 \\
\hline
\end{tabular}


The prevalence of depression among females was 48.7\% (95\% CI 24.0-73.3) and for males was 9\% (95\% CI $0 \%$ to $23.7 \%$ ). According to the results of articles, the prevalence of mild, moderate, and severe depression among Iranian infertile couples was 31.2\% (95\% CI $25.4-36.9$ ), $15.4 \%$ (95\% CI 11.5-19.4), and 13.7\% (95\% CI 9-17.6), respectively. More details were showed in Tables 2 and 3 and Fig. 2. Some studies calculated the mean and standard deviation of depression scores among understudy cases. The overall mean of depression score among Iranian couples was 7.74 [(95\% CI 5.52-9.93), $I^{2} 86.7, T^{2} 21.21, P$ heterogeneity < 0.001] (Fig. 3). Also, the mean of depression score according to different used tools was shown in Table 4. In terms of heterogeneity, the publication year, sex, and sample size does not have any significant effect on heterogeneity of between studies, but the depression measuring tools had a significant effect on heterogeneity between studies in the estimation of pooled prevalence. Also, in estimation pooled mean of depression score, the publication year, sex, measuring tools, and sample size had no effect on heterogeneity between studies (Table 5). According to Fig. 4 , the prevalence of depression had an increasing trend with the increase in sample size and publication year. Also, the mean of depression score among infertile couples had an increasing trend with the increase in sample size, but this score had a decreasing trend with the increase in a publication year.

\section{Publication bias}

The results of Begg and Egger's tests for prevalence were statistically significant ( $p=0.001$ for both tests), whereas the tests for estimation mean of depression score were not statistically significant $(p=0.11$ for both tests). It means for prevalence, the results of the Egger and Begg's test indicating that there is publication bias but for estimation mean of depression score there is no publication bias.

\section{Discussion}

Depression in infertile couples has been considered as one of the psychological problems in recent years. It cannot be denied that infertility is a concern for many people and should be taken into consideration. The results of this meta-analysis revealed that 35.3\% of Iranian infertile couples had depression, a disorder that can affect other aspects of health. In a systematic study by Masoumi in 2013 reported the prevalence of depression in infertile couples was 0.44 [11]. The

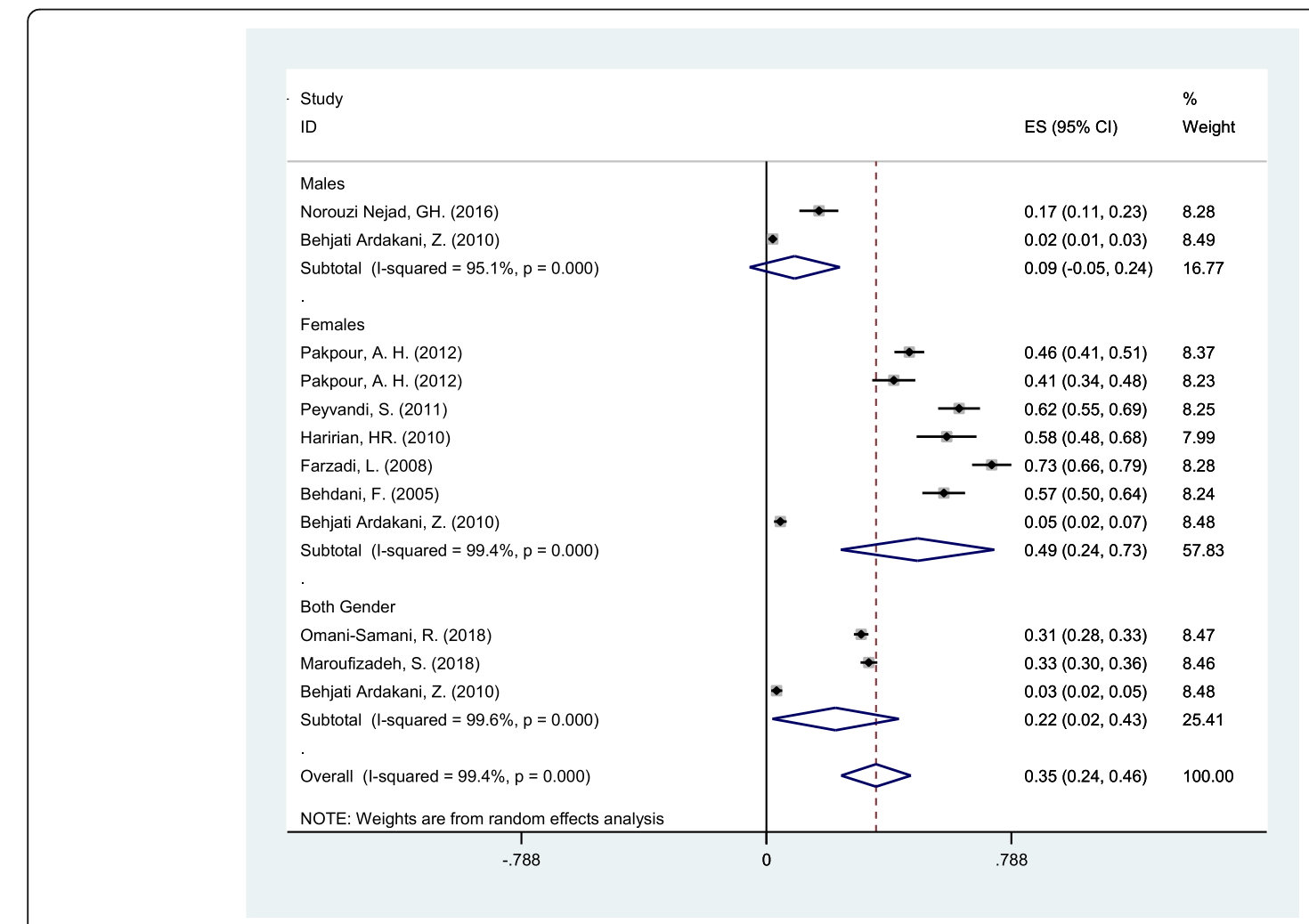

Fig. 2 Prevalence of depression among Iranian infertile couples 


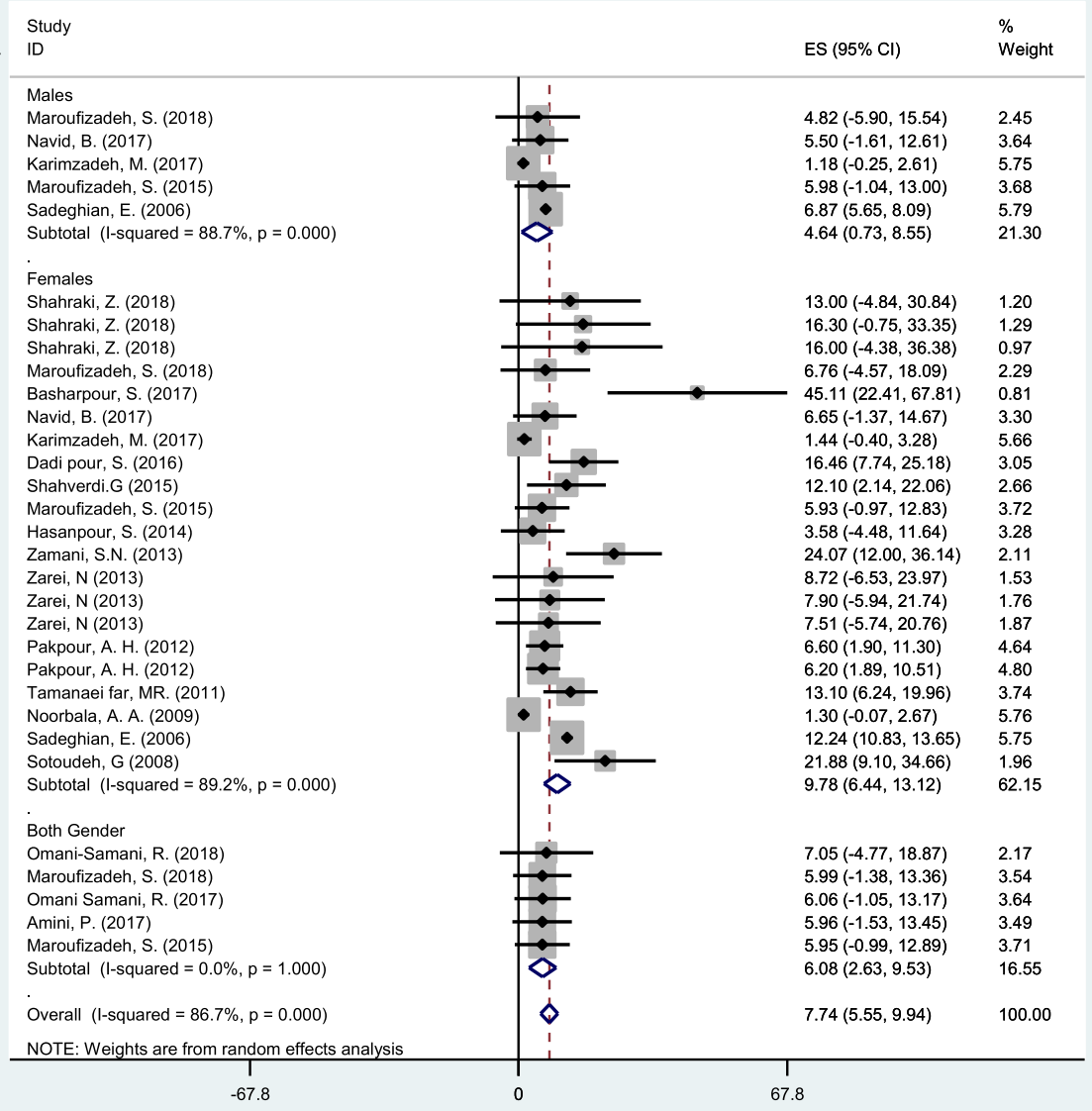

Fig. 3 The mean of depression score among Iranian infertile couples

Table 4 The pooled and subgroups of depression scores among Iranian couples

\begin{tabular}{|c|c|c|c|c|c|}
\hline Variable & Number of records & Sample size & Mean ( $95 \%$ confidence interval) & $T^{2}$ & $p^{2}$ \\
\hline \multicolumn{6}{|l|}{ Gender } \\
\hline Females & 21 & 3180 & $9.78(6.44$ to 13.11$)$ & 36.55 & 89.2 \\
\hline Males & 5 & 800 & $4.63(0.72$ to 8.54$)$ & 12.83 & 88.7 \\
\hline Both gender & 5 & 3927 & 6.08 (2.62 to 9.53$)$ & 0.00 & 0.00 \\
\hline \multicolumn{6}{|l|}{ Type of questionnaire } \\
\hline BDI & 5 & 349 & $19.77(13.03-26.52)$ & 0 & 0 \\
\hline Patients Health Questionnaire-9(PHQ-9) & 3 & 1686 & $6.13(-0.36$ to 12.63$)$ & 0 & 0 \\
\hline HADS & 10 & 3851 & $6.14(4.15$ to 8.13$)$ & 0 & 0 \\
\hline Depression, Anxiety, and Stress Scale (DASS) & 3 & 411 & 7.98 (0 to 16.09$)$ & 0 & 0 \\
\hline Cognitive Emotion Regulation Questionnaire (CERQ) & 1 & 322 & 45.11 (22.41 to 67.80$)$ & - & - \\
\hline The Symptom Checklist-90-Revised (SCL-90-R) & 5 & 678 & $4.61(0.33$ to 8.89$)$ & 23.29 & 97.8 \\
\hline Goldberg and Hiller Questioner (GHQ) & 4 & 610 & 11.23 (5.97 to 16.66$)$ & 12.83 & 41.9 \\
\hline Overall score & 31 & 7907 & 7.74 (5.52 to 9.93$)$ & 21.21 & 86.7 \\
\hline
\end{tabular}


Table $\mathbf{5}$ The result of meta-regression on the heterogeneity of pooled estimations

\begin{tabular}{|c|c|c|c|c|c|c|}
\hline \multirow{2}{*}{$\begin{array}{l}\text { Prevalence } \\
\text { Publication year }\end{array}$} & \multirow{2}{*}{$\begin{array}{l}\text { Coefficient } \\
0.00\end{array}$} & \multirow{2}{*}{$\begin{array}{l}\text { Standard error } \\
0.02\end{array}$} & \multirow{2}{*}{$\begin{array}{l}t \\
0.06 \\
\end{array}$} & \multirow{2}{*}{$\begin{array}{l}P>t \\
0.95\end{array}$} & \multicolumn{2}{|l|}{$[95 \% \mathrm{Cl}]$} \\
\hline & & & & & -0.04 & 0.04 \\
\hline Sex & -0.01 & 0.02 & -0.89 & 0.40 & -0.05 & 0.02 \\
\hline Measuring tools & -0.08 & 0.01 & -3.18 & 0.01 & -0.12 & -0.04 \\
\hline Sample size & 0.001 & 0.001 & -0.87 & 0.41 & -0.005 & 0.002 \\
\hline \multicolumn{7}{|c|}{ Mean score of depression } \\
\hline Publication year & -0.24 & 0.27 & -0.91 & 0.37 & -0.80 & 0.30 \\
\hline Sex & -1.81 & 1.43 & -1.27 & 0.21 & -4.75 & 1.12 \\
\hline Measuring tools & -1.05 & 0.58 & -1.81 & 0.08 & -2.23 & 0.13 \\
\hline Sample size & -0.001 & 0.003 & -0.45 & 0.53 & -0.009 & 0.006 \\
\hline
\end{tabular}

reason this study differs from our study is that this study has shown the prevalence of depression in infertile women in studies between 2000 and 2005, and our study included the results of studies 2005 to 2019. Also, the addition of further studies in our study that each article reports this index differently may be the reason for the differences in the findings of this study with the present study.

Studies in other countries also show a high prevalence of depression in infertile women. Recent researches showed that prevalence can range from 11 [48] to 18 [49] and 27 [50] and 73\% [41]. Dimitner et al. [51] reported that $19 \%$ of patients before the IVF cycle reported symptoms of moderate to severe depression, and $54 \%$ reported mild symptoms. Omu et al. [52] in Kuwait showed that the prevalence of depression in infertile women was $5.2 \%$ and $14.9 \%$ in men. A study in Taiwan [50] found that $40.2 \%$ of infertile women suffer from mental disorders, and 17\% suffer from severe depression. Another study in Sweden [48] reported that major depression was the most common mood disorder among infertile couples with a prevalence of $10.9 \%$ in women and $5.1 \%$ in men. In a study on infertile women in Nigeria [53], Upkong and colleagues showed that the prevalence of anxiety and depression in infertile women was $37.5 \%$ and $42.9 \%$, respectively. Similar studies have been done in different countries, and our study has been done in Iran. Consequently, the reason for the differences between the results of these studies and the present study may be due to differences in the place of study. Infertility seems to increase depression in women and men by affecting their moods, which is a serious health challenge. This should be considered a serious warning that threat the mental health of the infertile couples and should be the focus of special attention, particularly by the psychologist.
Some studies have reported a mean depression score based on the type of questionnaire used. In studies that used the BDI (Beck Depression Inventory) questionnaire to measure depression, the mean depression score was 20.95, based on the scoring [54]; participants had moderate depression. In studies using the PHQ (Patient Health Questionnaire), the mean depression score was 6.13, which according to the scoring [55]. Depression was moderate. Also, in studies using the HADS (Hospital Anxiety and Depression Scale) questionnaire, the mean depression score was 6.14, based on the scoring of this questionnaire [56]. In terms of depression, participants had normal status. As observed, studies have included this metaanalysis showed that depression has been mild in infertile couples, which is consistent with existing studies [57, 58]. Studies using other questionnaires to measure depression in infertile couples almost showed that depression is moderate or mild in participants.

This study showed that the prevalences of depression in infertile men and women were $9 \%$ and $48.7 \%$, respectively. These findings are consistence with the Samani et al. [59], Maroufizadeh et al. [57], and Hariri et al. [60] studies. In a study by Ahmadi [17], the prevalence of depression in infertile men in Tehran was $42 \%$, which is inconsistent with our study. It seems that because women are more involved with fertility and different aspects of infertility can affect women's mental health, women are more likely to be depressed than men.

There were a few limitations and potential biases in this study. Included studies may vary in the duration of the depression period of the study participants. So, the severity of depression cannot be the same across all included studies. Another limitation of this study is that studies may vary in quality and instrumentation used, making comparability difficult. Different questionnaires have also been used to measure 

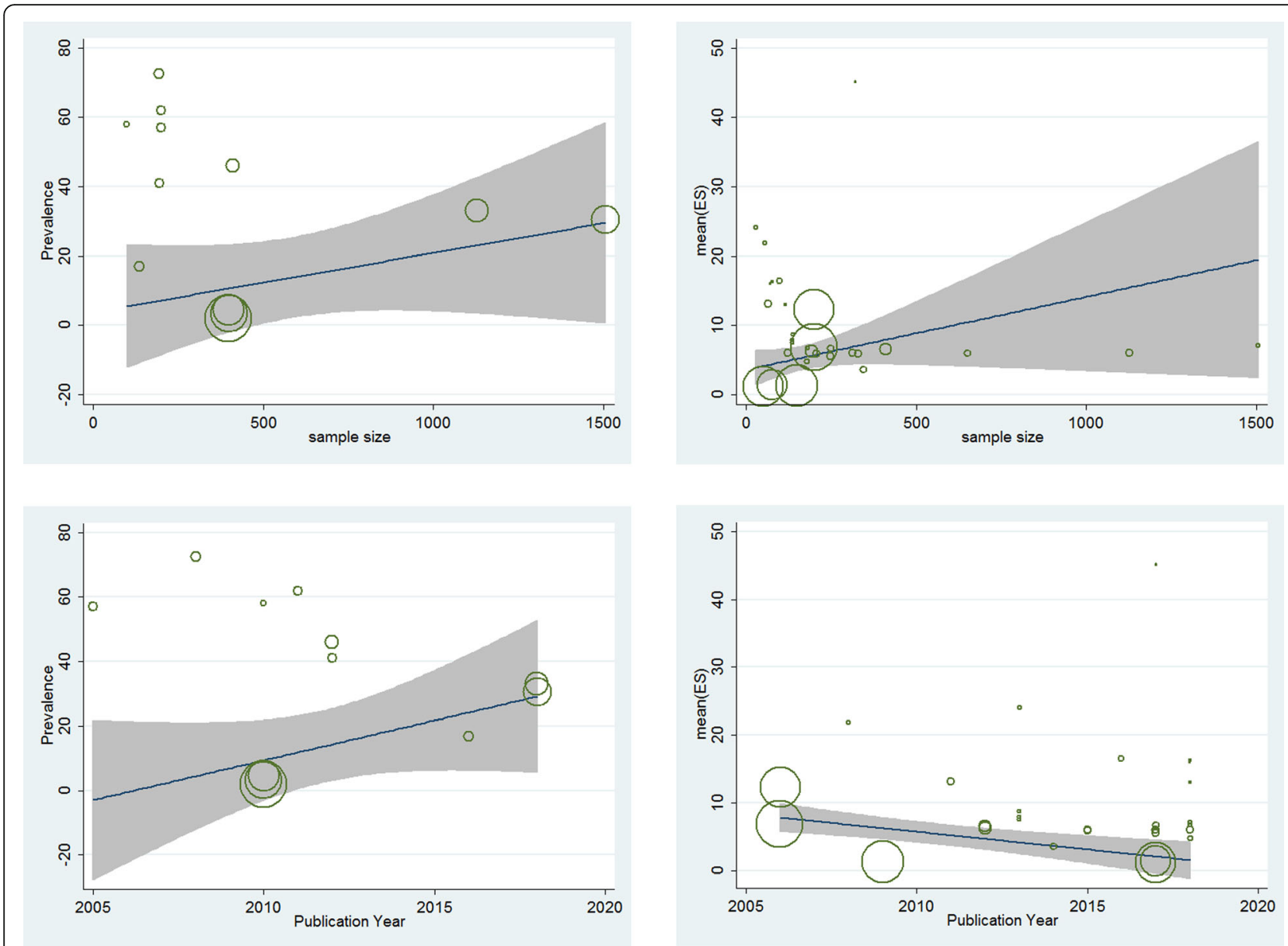

Fig. 4 The effect of different variables on heterogeneity between studies

depression, which makes it difficult to compare studies in terms of results.

\section{Conclusion}

Our study showed that $35.3 \%$ of infertile couples suffer from depression. The results can highlight an important and growing mental disorder among infertile couples that may be overlooked. Depression, as a major mental disorder, should be of particular concern to gynecologists, midwives, and physicians who manage infertile couples for fertility and related issues. However, many individuals, social, and cultural characteristics play an important role in the onset and exacerbation of depression, especially among infertile couples. Depression can occur in people of any age, gender, or background. It is predicted that in the whole world, depression alone will take second place in the disease burden until 2030. Also, according to this prediction, depression and anxiety disorders will be the main cause of the five factors that cause loss of life due to disability [61].

\section{Abbreviations}

DHS: Demographic and Health Surveys; PRISMA: Preferred Reporting Items for Systematic Reviews and Meta-Analyzes; MOOSE: Meta-analyses Of Observational Studies in Epidemiology

\section{Acknowledgements}

The authors wish to appreciate all the researchers whose articles were used in the present research.

\section{Authors' contributions}

YA contributed in the data analysis, manuscript preparation, and supervision. AM, MS, and FE contributed in the manuscript searching, manuscript preparation, and data analysis. RR contributed in the search strategy, article searching, and manuscript preparation. All authors have read and approved the manuscript.

\section{Funding}

This research did not receive any specific grant from funding agencies in the public, commercial, or not-for-profit sectors.

\section{Availability of data and materials}

Data will not be shared because they are completely included in the manuscript.

Ethics approval and consent to participate Not applicable 


\section{Consent for publication}

Not applicable.

\section{Competing interests}

The authors declare that they have no competing interests.

\section{Author details}

${ }^{1}$ Pars Advanced and Minimally Invasive Medical Manners Research Center, Pars Hospital, Iran University of Medical Sciences, Tehran, Iran. ${ }^{2}$ Department of Epidemiology and Biostatistics, School of Public Health, Tehran University of Medical Sciences, Tehran, Iran. ${ }^{3}$ Health Research Center, Life Style Institute, Baqiyatallah University of Medical Sciences, Tehran, Iran. ${ }^{4}$ Department of Epidemiology and Biostatistics, Faculty of Health, Baqiyatallah University of Medical Sciences, Tehran, Iran. ${ }^{5}$ Department of Public Health, School of Public Health, Maragheh University of Medical Sciences, Maragheh, Iran ${ }^{6}$ Social Determinants of Health Research Center, Research Institute for Health Development, Kurdistan University of Medical Sciences, Sanandaj, Iran.

\section{Received: 7 November 2019 Accepted: 13 April 2020}

Published online: 04 May 2020

\section{References}

1. WHO. Available: https://www.who.int/reproductivehealth/topics/infertility/ multiple-definitions/en/. 2019.

2. WHO. Available: https://www.who.int/reproductivehealth/topics/infertility/ perspective/en/. 2019.

3. WHO. Available: https://www.who.int/reproductivehealth/topics/infertility/ burden/en/. 2019.

4. Akhondi MM, Ranjbar F, Shirzad M, Behjati Ardakani Z, Kamali K, Mohammad K (2019) Practical difficulties in estimating the prevalence of primary infertility in Iran. Int J Fertil Steril. 13(2):113-117

5. Sargolzaee MR, Moharreri F, Arshadi HR, Javadi K, Karimi S, Fayyazi-bordbar MR. Psychosexual and depression disorders in infertile female referring to mashhad infertility treatment center. Journal of Reproduction \& Infertility. 2001;2(4).

6. Tanha FD, Mohseni M, Ghajarzadeh M (2014) Sexual function in women with primary and secondary infertility in comparison with controls. Int J Impotence Res 26(4):132

7. who. Available: https://www.who.int/reproductivehealth/topics/infertility/ en/. 2019

8. Montazeri A, Mousavi S, Omidvari S, Tavousi M, Hashemi A, Rostami T (2013) Depression in Iran: a systematic review of the literature (2000-2010)

9. El Kissi Y, Romdhane AB, Hidar S, Bannour S, Idrissi KA, Khairi H et al (2013) General psychopathology, anxiety, depression and self-esteem in couples undergoing infertility treatment: a comparative study between men and women. Eur J Obstetr Gynecol Reprod Biol 167(2):185-189

10. Drosdzol A, Skrzypulec V (2009) Depression and anxiety among Polish infertile couples-an evaluative prevalence study. J Psychosom Obstetric Gynecol 30(1):11-20

11. Masoumi SZ, Poorolajal J, Keramat A, Moosavi SA (2013) Prevalence of depression among infertile couples in Iran: a meta-analysis study. Iran J Public Health 42(5):458

12. WHO. Available: https://www.who.int/mental_health/management/ depression/en/. 2019.

13. Garnefski N, Kraaij V, Schroevers MJ, Somsen GA (2008) Post-traumatic growth after a myocardial infarction: a matter of personality, psychological health, or cognitive coping? J Clin Psychol Med Settings. 15(4):270

14. Seif D, Alborzi S, Alborzi S. Effect of some affective and demographic variables on life satisfaction of infertile women. Journal of Reproduction \& Infertility. 2001;2(4).

15. Ramezanzadeh F, Aghssa MM, Abedinia N, Zayeri F, Khanafshar N, Shariat M et al (2004) A survey of relationship between anxiety, depression and duration of infertility. BMC Womens Health 4(1):9

16. WHO. Available: https://www.who.int/en/news-room/fact-sheets/detail/ depression. 2019.

17. Ahmadi H, Montaser-Kouhsari L, Nowroozi MR, Bazargan-Hejazi S (2011) Male infertility and depression: a neglected problem in the middle east. J Sex Med 8(3):824-830

18. Rahmati S, Delpisheh A, Moghadam AD, Sayehmiri K, Mohamadian F (2019) Survey frequency of the depression and anxiety levels of infertile women in western Iran. Med J Indonesia 28(1):35-39
19. Shahraki Z, Tanha FD, Ghajarzadeh M. Depression, sexual dysfunction and sexual quality of life in women with infertility. BMC women's health. 2018;18(1).

20. Omani-Samani R, Maroufizadeh S, Almasi-Hashiani A, Amini P (2018) Prevalence of depression and its determinant factors among infertile patients in Iran based on the PHQ-9. Middle East Fertil Soci J 23(4):460-463

21. Maroufizadeh S, Hosseini M, Rahimi Foroushani A, Omani-Samani R, Amini P. The effect of depression on quality of life in infertile couples: an actorpartner interdependence model approach. Health and quality of life outcomes. 2018;16(1)

22. Maroufizadeh S, Ghaheri A, Almasi-Hashiani A, Mohammadi M, Navid B, Ezabadi Z et al (2018) The prevalence of anxiety and depression among people with infertility referring to Royan Institute in Tehran, Iran: a cross-sectional questionnaire study. Middle East Fertil Soc J 23(2):103106

23. Basharpoor S, Atadokht A, Ghaffari M, Mowlaie M (2017) Prediction of depression through cognitive emotion regulation and resilience among infertile females. J Nurs Educ 4(4):34-42

24. Samani RO, Vesali S, Navid B, Vakiliniya B, Mohammadi M (2017) Evaluation on hope and psychological symptoms in infertile couples undergoing assisted reproduction treatment. Int J Fertility Sterility 11(2):123-129

25. Omani Samani R, Maroufizadeh S, Navid B, Amini P (2017) Locus of control, anxiety, and depression in infertile patients. Psychol Health Medicine 22(1):44-50

26. Navid B, Mohammadi M, Vesali S, Mohajeri M, Samani R (2017) Correlation of the etiology of infertility with life satisfaction and mood disorders in couples who undergo assisted reproductive technologies. Int J Fertility Sterility 11(3):205-210

27. Karimzadeh M, Salsabili N, Akbari Asbagh F, Teymouri R, Pourmand G, Soleimanieh NT (2017) Psychological disorders among Iranian infertile couples undergoing assisted reproductive technology (ART). Iran J Public Health 46(3):333-341

28. Amini P, Maroufizadeh S, Samani RO (2017) Evaluating the factor structure, item analyses, and internal consistency of hospital anxiety and depression scale in Iranian infertile patients. Int J Reprod BioMed 15(5):287-296

29. Dadipoor S, Alavi A, Zarei F, Safari-Moradabadi A (2016) Mental health of infertile women in Bandar Abbas. J Prev Med 3(2):20-28

30. Shahverdi J, Ahmadi S, Sadeghi K, Bakhtiari M, Rezaei M, Wissie F, et al. Comparison of mental health, happiness, inferiority, marital satisfaction and marital conflict in infertile and fertile women in Kermanshah. Clin Res Paramed Sci. 2016;4(3):-

31. Maroufizadeh S, Karimi E, Vesali S, Omani SR (2015) Anxiety and depression after failure of assisted reproductive treatment among patients experiencing infertility. International J Gynecol Obstetrics 130(3):253-256

32. Hasanpour S, Bani S, Mirghafourvand M, Yahyavi KF (2014) Mental health and its personal and social predictors in infertile women. J Caring Sci 3(1): $37-45$

33. Zamani N, Ghasemi M, Jokar E, Khazri Moghadam N (2013) Comparison of depression and life quality of fertile and infertile women and those with frequent abortions. J Babol Univ Medi Sci 15(6):78-83

34. Zarei N, Rasoolzadeh Tabatabai K, Azin SA. Comparison of depression, anxiety and stress in first, second and third trimesters of pregnancy in normal pregnant women and women undergoing infertility treatment health psychology. 2013;4

35. Pakpour AH, Yekaninejad MS, Zeidi IM, Burri A (2012) Prevalence and risk factors of the female sexual dysfunction in a sample of infertile Iranian women. Arch Gynecol Obstetrics 286(6):1589-1596

36. Tamannai Far MR (2011) A Comprative Study of mental health, marital adjustment and coping responses among fertile-infertile women. Clin Psychol Personality 2(4):51-60

37. Peyvandi S, Hosseini SH, Daneshpoor SMM, Mohammadpour RA, Qolami N (2011) The prevalence of depression, anxiety and marital satisfaction and related factors in infertile women referred to infertility clinics of Sari city in 2008. J Mazandaran Univ Med Sci 20(80):25-32

38. Haririan H, Mohammadpour $Y$, Aghajanloo A (2010) Prevalence of depression and contributing factors of depression in the infertile women referred to Kosar Infertility Center, 2009. Irain J Obestetric Gynecol Infertility 2(13):45-49

39. Noorbala AA, Ramezanzadeh F, Abedinia N, Naghizadeh MM (2009) Psychiatric disorders among infertile and fertile women. Soc Psychiatr Psychiatr Epidemiol 44(7):587-591

40. Faraji R, Milani F, Danesh M (2009) O287 Realative frequeny of depression in infertile women, Rasht, Iran. Int J Gynecol Obstetrics 107:S174-S1S5 
41. Farzadi L, Ghasemzadeh A (2008) Two main independent predictors of depression among infertile women: an Asian experience. Taiwan J Obstetrics Gynecol 47(2):163-167

42. Sadeghin E, Heidarian-poor A, Abed F (2006) Comparison of psychiatric problems in infertile men and women referring to infertility clinic of Hamadan Fatemyeh Hospital. J Arak Univ Med Sci 9(2):31-39

43. Bahdani F, Erfanian M, Habrani P, Hojjat SK (2005) Prevalence of depression and its related factors in infertile women referred to Montaserieh Infertility Clinic in Mashhad. Prin Mental Health 23-24:141-147

44. Yassini M, Khalili MA, Hashemian Z (2005) The level of anxiety and depression among Iranian infertile couples undergoing in vitro fertilization or intra cytoplasmic sperm injection cycles. J Res Med Sci 10(6):358-362

45. Noruzinejad GH, Mohammadi SD, Seyedtabaee R, Sharifi AH (2016) An investigation of the prevalence rate and severity of symptoms of depression and its relationship with duration of infertility among infertile men referred to Infertility Center Jahad Daneshgahi Qom in 2013, Iran. Qom Univ Med Sci J 10(2):81-87

46. Behjati Ardakani Z, Akhondi MM, Kamali C, Fazli Khalaf Z, Eskandari S, Ghorbani B (2011) Evaluation of mental health of infertile people referred to Ibn Sina Infertility Center. J Reprod Infertility 4(11):319-324

47. Sotoudeh G, Siasi F, Lesan S, Mirdamadi SR, Chameri M (2008) Frequency of anxiety and depression and its related factors in women with elevated blood androgen levels. Iran J Med Sci Organ 4(25):482-489

48. Volgsten H, Skoog Svanberg A, Ekselius L, Lundkvist Ö, Sundström Poromaa I Prevalence of psychiatric disorders in infertile women and men undergoing in vitro fertilization treatment. 2008;23(9):2056-63.

49. Chiaffarino F, Baldini MP, Scarduelli C, Bommarito F, Ambrosio S, Dorsi C, et al. Prevalence and incidence of depressive and anxious symptoms in couples undergoing assisted reproductive treatment in an Italian infertility department. 2011;158(2):235-41

50. Chen T-H, Chang S-P, Tsai C-F, Juang K-D. Prevalence of depressive and anxiety disorders in an assisted reproductive technique clinic. 2004;19(10):2313-8.

51. Demyttenaere K, Bonte L, Gheld of M, Vervaeke M, Meuleman C, Vanderschuerem D, et al. Coping style and depression level influence outcome in in vitro fertilization. 1998;69(6):1026-33.

52. Omu FE, Omu AE. Emotional reaction to diagnosis of infertility in Kuwait and successful clients' perception of nurses' role during treatment. 2010;9(1):5.

53. Upkong D, Orgi E (2006) Mental health of infertile women in Nigeria

54. García-Batista ZE, Guerra-Peña K, Cano-Vindel A, Herrera-Martínez SX, Medrano LA (2018) Validity and reliability of the Beck Depression Inventory (BDI-II) in general and hospital population of Dominican Republic. PLoS One 13(6):e0199750-e019975e

55. Löwe B, Kroenke K, Herzog W, Gräfe KJJoad. Measuring depression outcome with a brief self-report instrument: sensitivity to change of the Patient Health Questionnaire (PHQ-9). 2004;81(1):61-6.

56. Snaith RP (2003) The Hospital Anxiety And Depression Scale. Health Qual Life Outcomes 1:29

57. Maroufizadeh S, Karimi E, Vesali S, Omani Samani R. Anxiety and depression after failure of assisted reproductive treatment among patients experiencing infertility. 2015;130(3):253-6.

58. Pakpour AH, Yekaninejad MS, Zeidi IM, Burri A. Prevalence and risk factors of the female sexual dysfunction in a sample of infertile Iranian women. 2012; 286(6):1589-96.

59. Samani RO, Vesali S, Navid B, Vakiliniya B, Mohammadi M. Evaluation on hope and psychological symptoms in infertile couples undergoing assisted reproduction treatment. 2017;11(2):123.

60. Haririan HR, Mohammadpour Y, Aghajanloo A, Gynecology, Infertility. Prevalence of depression and contributing factors of depression in the infertile women referred to Kosar infertility center, 2009. 2010;13(2):45-9.

61. Mathers CD, Loncar DJ (2006) Projections of global mortality and burden of disease from 2002 to 2030. Plus Med 3(11):e442

\section{Publisher's Note}

Springer Nature remains neutral with regard to jurisdictional claims in published maps and institutional affiliations.

\section{Submit your manuscript to a SpringerOpen ${ }^{\circ}$ journal and benefit from:}

- Convenient online submission

- Rigorous peer review

- Open access: articles freely available online

- High visibility within the field

- Retaining the copyright to your article

Submit your next manuscript at $\boldsymbol{\nabla}$ springeropen.com 